\title{
Gender and Prison Recidivism: The Influence of Protective and Risk Factors
}

\author{
Cinsiyet ve Cezaevi Koşulları Bakımından Tekerrür: Koruyucu \\ Faktörler ve Risk Faktörlerinin Etkisi
}

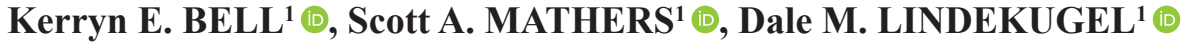

${ }^{1}$ Eastern Washington University, Department of Sociology \& Criminal Justice, Washington, USA

ORCID: K.E.B. 0000-0003-3727-1720; S.A.M. 0000-0001-9491-162X; D.M.L. 0000-0002-2346-4735

\section{ABSTRACT}

Recidivism after incarceration is a fundamental concern for the criminal justice system. Although men remain the largest percentage of the prison population, women are entering prison at an increasing frequency. Insufficient research has looked at the influence of prison protective and risk factors on recidivism by gender or any theoretical model to consider this increase in the female prison population. Using data from a large western state in the USA, all male and female inmates incarcerated from 2009 through 2011 are evaluated in terms of protective (education, programming, community ties, relationship status) and risk factors (race/ethnicity, age, homelessness, prison conduct, gang membership, prison sentence length and type) associated with their initial incarceration or recidivism. The findings and implications are subsequently discussed.

Keywords: Prison, Gender, Recidivism 


\section{Introduction}

Recidivism ${ }^{1}$ following incarceration is a fundamental concern for those interested in effective criminal justice and public safety in general. Although men remain the largest percentage of the prison population, women are entering prison at an increasing frequency, adding to issues of recidivism. Two important questions to consider are 1) What protective and risk factors influence recidivism? and 2) Does gender influence the protective and risk factors associated with recidivism? Unfortunately, studies focusing on gender specific correlates of recidivism are rare (Stuart \& Brice-Baker, 2004; Collins, 2010, Olson et al., 2016). Furthermore, prior research does not take into account any theoretical lens such as the importation and deprivation models to explain this relationship.

The few studies on gender specific correlates of recidivism that do exist focus on the importance of age (younger), children, and substance abuse (Scott et al., 2014). Collins (2010), in a meta-analysis of 57 studies of violent and nonviolent recidivism among men and women, found that the foremost gap in current knowledge is that there is not enough data on women and recidivism. She also found that many studies that included women along with men in the sample, did not account for gender differences. Additionally, pathways to prison are different for women as they include homelessness, trauma histories, and subsequent substance abuse and mental health issues (see Benda, 2005; Fedock et al., 2013; Huebner et al., 2010). The current study will contribute to filling the gap on gender and recidivism by examining data from a large western state in the USA on all male and female inmates incarcerated from 2009 through 2011. It also expands on the limitations of previous studies by incorporating a theoretical lens.

In those studies that do look at differences in correlates of recidivism between men and women, the findings are mixed. Makarios et al. (2010) specifically looked at differences in factors related to recidivism between male and female offenders. While they found that employment, housing and completion of some forms of treatment were negatively associated with multiple measures of recidivism, they did not vary by gender. McCoy and Miller (2013) found no differences across gender for risk factors but did find some prosocial support in protective factors correlating with female recidivism.

1 While the definition of recidivism is broad and can include such ideas as violating parole or probation, solely those who are re-incarcerated are the focus in this research. 
Other studies found some variations in recidivism by gender. For example, Olson et al. (2016) found several gender specific correlates of recidivism. Prior incarceration, time served, and types of prior arrest histories had differential associations by gender with both overall recidivism and violent recidivism. Age, race, and conviction offense were gender specific risk factors for overall recidivism and education level and marital status were gender specific risk factors for violent recidivism.

A discussion of correlates of recidivism include both protective factors that, when present, decrease the likelihood of recidivism, and risk factors that, when present, increase the likelihood. The current research analyzes the protective factors (education, programming, community ties and relationship status) and the risk factors (age, race/ethnicity, homelessness, prison conduct, gang membership and prison sentence length and type) associated with recidivism. In particular, this study is important when it looks at homelessness and gang membership and their ties to recidivism since previous research suggests that pathways to prison are different for men and women with women more likely to be homeless (see Fedock et al., 2013). All are tested to determine whether their influences, if any, are gender specific. This study also assesses these protective and risk factors through the theoretical lens of the importation and deprivation models. To that end, the protective factors of education, community ties, and relationship status as well as the risk factors of age, race/ ethnicity, homelessness, and gang membership represent importation. The protective factors of programming and risk factors of prison conduct and prison sentence length and type represent deprivation.

\section{Theoretical Framework}

Two theoretical models - deprivation and importation originally developed by Gresham Sykes are commonly used to explain inmate adaptation to prison. The deprivation model says inmate actions result from stressful and sometimes oppressive conditions inherent in incarceration itself(Cao et al., 1997, Sykes, 2007). Alternatively, the importation model suggests that characteristics of an individual that predate confinement (such as gender), and extra-prison factors during confinement (such as ties to the community) impact inmate adjustment (Cao et al., 1997; Sykes, 2007; Thomas \& Peterson, 1977).

However, critiques exist of both models. Thomas and Foster (1973) critique the deprivation model for presenting the prison as a "closed system" and for failing to 
account for pre-prison and extra-prison experiences in influencing values and role adaptations of those incarcerated. They insightfully present the importation model not as an alternative to deprivation but rather as an approach that would "expand the scope" of the deprivation approach. To support their contention, they test two pre-prison factors (social class and age at first involvement in criminal behavior) and two extra-prison factors (contact with individuals outside the prison and post prison expectations) as predictors of prosocial role adaptations. Their findings support the need to include pre and extra- prison factors in examining adjustment to prison.

It is argued that deprivation and importation factors can have an impact on prison adjustment when someone reoffends and is sentenced to prison again. The current research includes indicators of the pre-prison protective and risk factors of education, age, race/ethnicity, homelessness, and gang membership. Indicators of extra-prison factors consist of ties to the community and relationship status. Deprivation withinprison factors in the current study are programming, prison conduct, and sentence length and type.

More support for the importation model related predictors of recidivism and differences among males and females in correlates of protective and risk factors impact on reoffending are expected. It is also expected that the relational oriented protective factors of relationship status and ties to the community will more strongly predict variation in recidivism for women than for men. This research thus seeks to explore predictors of recidivism to see whether some are gender specific and also contribute to the importation and deprivation models of prison adjustment by identifying which pre and extra-prison factors (importation) correlate with recidivism and which within-prison factors (deprivation) also do so.

\section{Protective Factors}

\subsection{Education}

Education is used as a pre-prison protective factor and has long been associated with better outcomes for inmates upon release and lower rates of recidivism (Gerber \& Fritsch, 1995; Harer, 1995; Jancic, 1998; Tracy et al., 1998). Despite some contrary findings (Davis, 1985; Martinson, 1974; and Piehl, 1998), education programs, along with other types of programming, have been increasing in number and variety in the 
last 20 years (Phelps, 2011). Specifically, completion of a GED ${ }^{2}$ is associated with less recidivism for female offenders (Brewster \& Sharp, 2002; Esperian, 2010).

Further research points to the importance of education. In a review of research on the effect of prison education programs on recidivism, Esperian (2010) concluded that education for inmates reduced recidivism dramatically and cited a U.S. Department of Justice report that prison-based education is the single most effective tool for lowering recidivism (Education Services Newsletter, 2009). Tietjen et al. (2018) suggest that education is actually the most powerful correlate of decreased recidivism. Yet the effect of education in these studies was not tested regarding potential gender differences.

Collins' (2010) meta-analysis of the effect of gender on recidivism found that the education level of inmates was predictive of recidivism, but the effect was homogeneous across gender. Yet Huebner and Pleggenkuhle (2015) determined that possessing a high school diploma (along with a stable work history) was predictive of being less likely to recidivate in a female sample but not in a male sample. Alternatively, Huebner et al. (2010) found having less education was tied to a faster return to recidivism among women. Makarios et al. (2010) found that completion of educational or vocational training had no impact on recidivism for either men or women.

In addition, research by Brewster and Sharp (2002) found that completion of a GED in prison was strongly associated with longer survival times outside of prison for both men and women but more so for women. They suggested that the efficacy of the GED in prison might be particularly salient for women because a majority of female offenders have children and, because of pregnancy, had dropped out of school. They also noted that completion of vocational-technical training while incarcerated was associated with shorter survival times for both women and men although vocational programs worked better for younger inmates while educational programs did not. Interestingly Brewster and Sharp (2002) noted that the effect of the GED seemed to be conditioned by the length of sentence. Inmates who completed a GED and had longer sentences fared better post-release than those with shorter sentences. Inmates who completed GED's with shorter prison sentences recidivated sooner.

2 A GED (General Educational Development) test can provide certification of high-school level academic skills in the United States. It is an alternative to a US high school diploma. 
It may be the case that extensive education better reduces recidivism. The longer the process, the more investment required of the inmate. This may result in increased personal growth because of a longer dedication to course work. The implication is that it is more about developing habits of personal responsibility, timeliness, and a work ethic than about academic content (Brewster \& Sharp, 2002). The development of personal growth and responsibility is the primary goal of most prison programming.

\subsection{Programming}

In this study, programming refers to within prison programs other than educational (including vocational education). Previous research suggests that substance use is tied to recidivism (Collins, 2010; Huebner et al., 2010; Jones \& Sims, 1997; Mills, Kroner, \& Hemmati, 2003). In their meta-analysis of 68 studies assessing the impact of correctional treatment on misconduct, French and Gendreau (2006) found that behavioral treatment programs (rather than non-behavioral such as educational or vocational programs) had the strongest effects on reducing recidivism and that programs associated with the most reductions in misconduct were also associated with larger reductions in recidivism. These findings were consistent with previous meta-analyses conducted by Keyes (1996) and Morgan and Flora (2002). Yet, as is common in the literature on recidivism, there is a lack of differentiation by gender. In predicting recidivism of men and women, Makarios et al. (2010) determined that those who completed substance abuse treatment, sex offender treatment and other programming were significantly less likely to recidivate and that these effects were not gender specific.

Additional research has explored prison programming. Fedock et al. (2013) explored gender differences in service needs for incarcerated adults in an urban jail. They noted that women in their sample had higher rates of homelessness (prior to incarceration and anticipated homelessness upon release), serious mental illness, substance abuse disorder, and trauma histories. Gender differences in needs imply gender differences in influences on recidivism and gender sensitive programming targeting those needs. This is particularly important as drug treatment reduces recidivism for both men and women (Olson et al., 2016).

Phelps (2011), points out that programs designed to foster successful reintegration are increasing nationwide and that offerings are expanding to include more interpersonal and practical interventions. He also advocates for gender specific 
programming for men in order to address issues of hyper-masculinity, often exacerbated by the prison environment. Karp (2010) argues that incarceration disintegrates men because they need to put on a mask of hyper-masculinity as a means to cover emotions and the need for support encompassed in the concept of doing one's own time. To do this the inmate must break conventional relationships and not allow others to provide support in order to avoid being seen as weak and a target. The prison environment blocks commitment and attachment because the norm of doing one's own time renders conventional commitments and attachments a sign of weakness.

Gender is clearly a significant factor in determining which types of programs are better suited for inmates. Programming for women usually takes into account the different offenses typically committed by women (i.e. drug addiction) that underlie incarceration rates (Collins 2010; Calhoun et al. 2010; Baradon et al. 2008). While for men, hyper-masculinity may be a serious underlying issue, for women it may be that relational ties are more significant. Calhoun et al. (2010) argue that women tend to conceptualize their self-worth in the relationships they establish with others. Recidivism, in the form of drug relapses, is entwined with relationship conflict and damage. This would imply that ties to the community might be more important for women than men in impacting the likelihood of recidivism.

\subsection{Community Ties and Relationship Status}

For an inmate, contact with family and friends extra-prison are events fostering the primary social ties known to encourage conventional behavior (Hirshi, 1969). A growing body of literature focusing on visitation examines the relationship between inmates, family relationships, and recidivism (Berg \& Huebner 2010; Bates \& Mears 2008; Ryan \& Yang 2005; Casey-Acevedo et al. 2004; Bayse, Allgood, and Van Wyk 1991; Holt \& Miller 1971). Generally, these studies find that visitation conveys family support that in turn reduces infractions, encourages programming, and mitigates the inevitable burdens of the re-entry process.

Contact with family provides an opportunity for mending and maintaining family relationships as well as increasing the inmates' perception that families will provide support after incarceration. According to Bayse et al. (1991), inmates who could maintain family relationships were less likely to offend on the outside, and inmates with more frequent visitation were less likely to recidivate (see Bates \& Mears, 2008). 
Mitchell et al. (2016) find that visitation reduces recidivism for both men and women and has a larger effect for men.

Schafer (1994) reports that for male inmates, wives are more consistent visitors than parents, but the relationship is full of unique stressors, leading to a reduction or an end to visitation. Therefore, although the frequency, duration, priority, and intensity of these relationships are typically high, and normally control theories would contend those relationships as ideal, the outcome did not lead to desistance. However, other research on visitation examines ties to recidivism and suggests that greater frequency of visitation is most important to reduce recidivism (see Bales \& Mears, 2008; Minnesota Department of Corrections, 2011).

Relationship status can impact visitation with more family contact and support reducing recidivism (Barrick et al., 2014; Taylor, 2015). In terms of relationships, the findings regarding marital status and recidivism are mixed. Prior research has examined the effect of marriage for both men and women, finding a stronger protective factor for men and differential impact on women (see Cobbina et al., 2012). Taylor (2015) find that living with an intimate partner tends to blunt the effect of prior criminal behavior as well as dissuade men from beginning criminal behavior (Taylor, 2015).

A gendered impact of relationships can also be seen. Women who are living with an intimate partner are more likely to both recidivate as well as be led into criminal behavior. Furthermore, research specifically focusing on a women's "propensity to marry" finds that women with a low or high "propensity to marry" are more likely to engage in criminality relative to women with a moderate "propensity to marry". This finding further blurs the relationship between marriage and recidivism. Taylor (2015) views "propensity to marry" as a series of factors pertaining to educational expectations, work experiences, relationship perceptions, etc. which cast the variable in light of the desirable/undesirable aspects one might find in a female partner. Benda (2005) finds that living with a criminal partner is a stronger predictor of recidivism for women than men. Thus, it is important to see whether a gendered effect on recidivism exists for visitation and relationship status.

Overall among protective factors, some gender differences are seen when looking at the impact of education and relationship status. However, other research shows results are mixed. Most importantly, very little previous research has examined 
whether protective factor correlates are gendered in their impact on reoffending (see Bates and Mears, 2008; Makarios et al., 2010; Olson et al., 2016; Taylor, 2015; Tietjen et al., 2018) or represent support for an importation or deprivation model of prison. This study assesses the correlates of protective factors education, community ties and relationship status (importation), and protective factor programming (deprivation) on reoffending by gender.

\section{Risk Factors}

\subsection{Race/Ethnicity}

Research on race/ethnicity as a gender specific correlate of recidivism representing importation is mixed. Belknap (1996) concluded that race/ethnicity is a gender specific correlate and that White women were more likely than Black women to benefit from "chivalry" and less likely to recidivate. Cobbina et al. (2012) found race/ ethnicity not to be a significant correlate of recidivism for males but Black females failed more quickly upon release than White females. Olson et al. (2016) likewise determined race/ethnicity to be a gender specific correlate.

In their sample the odds of Black men being rearrested was over $50 \%$ higher than for Whites yet race was not a significant correlate of recidivism for women. McCoy and Miller (2013) determined race/ethnicity was not a significant correlate of recidivism for either men or women. Interestingly, these studies have not included race/ethnicity other than a White, non-White dichotomy when looking at recidivism, which this study does.

\subsection{Age}

Age as a measure of importation is often used as a control variable in studying prison populations as younger inmates are more likely to be involved in infractions, violent infractions and, upon release, to recidivate. However, some variation by gender has been found (see Jones \& Sims, 1997; McCoy \& Miller, 2013; Olson et al., 2016). Collins' (2010) meta-analysis of the literature on recidivism found age to be a consistent correlate of recidivism. Stuart and Brice-Baker (2004), in a sample of female prisoners, found age, along with number of convictions, to be the strongest correlates of recidivism.

Findings tend to indicate that age is a strong correlate of recidivism for both men and women (Uggen, 2000). Jones and Sims (1997) found age to be a significant 
correlate of rearrests for property offenses for both men and women and Huebner and Pleggenkuhle (2015) found that age was a significant correlate in delaying time to failure of parole. Cobbina et al. (2012) determined age to significantly predict how quickly male and female offenders failed on release and Olson et al. (2016) determined age, along with total prior arrests, to be the strongest correlates of women's and men's overall recidivism. Age was also a significant correlate for both genders in predicting violent recidivism. McCoy and Miller (2013), in matched pair's samples of women and men likewise found age to be a significant correlate of recidivism for both genders but they did note that men and women tend to reoffend with different types of offenses.

\subsection{Homelessness}

Previous research suggests that women are more likely than men to be homeless before and after incarceration (Fedock, Fries, \& Kubiak, 2013). Solinos-Saunders \& Stacer (2017) found the strain of abuse, family disorganization, and homelessness were more significantly associated with repeated incarceration for women than men. Further, Stuart and Brick-Baker (2004) find that economic marginalization differentially impacts women's propensity to recidivate. Certainly, homelessness can be tied to economic marginalization and Jurik (1983) found that economic need contributed greatly to female recidivism. This study is actually able to assess the specific impact of homelessness representing importation's impact on recidivism by gender.

\subsection{Gang Membership}

Scholarship has documented the potential implications of in-prison experiences for prison recidivism (Huebner et al., 2007). Cochran et al. (2014) found that inmates who engaged in prison misconduct (violent in particular), were more likely to recidivate. A large part of in prison misconduct for men is gang related. One Canadian study that looked at gender and gang offending found that female gang members also displayed more violence and were more likely to have served prior prison sentences (Scott \& Ruddell, 2011). However, it is much less common for women to be involved with gangs in prison than men (Lauderdale \& Burman, 2009). Further, gang membership puts men at greater risk of recidivism (Dooley et al., 2014; Huebner et al., 2007). This study assesses the impact of gang membership on recidivism for both men and women. 


\subsection{Sentence Type and Length}

Previous research on prison recidivism also suggests that the length of a prison sentence can exert an influence (Mears et al., 2016) and can be used to represent the deprivation model of prison. Again, despite much research on sentence types and sentence length as correlates of recidivism, there is little on whether they are gender invariant or specific. Cobbina et al. (2012) found drug offenders to have higher rates of recidivism than any other type of offense and some correlates were gender specific. In their study, drug use for women was specifically conditioned by relationships with abusive partners, relationships with adults who brought young women into the drug culture, and as part of maintaining a relationship with a drug-using boyfriend. Regarding recidivism, they found that drug convictions predicted women's re-arrest but not men's. This pattern was especially true for minority women (Cobbina et al., 2012). It appears that a negative relationship with a male counterpart conditions the relationship between the drug conviction and recidivism for women implying that recidivism may be relational for women but not men. This is consistent with the findings regarding gender differences in the nature and quality of social ties reviewed in examining protective factors.

Additionally, there is support for the idea that some of the relationship between drug offenses and recidivism revolves around how offenders take advantage of their time in prison and that this may vary by gender. According to Brewster and Sharp (2002), inmates charged with drug distribution and who also completed a GED or vocational program had better post-release outcomes compared to those who did not complete any programs. According to the authors, these inmates were selling drugs to compensate for a lack of education and job training. This was consistent with their reporting that receiving a GED has a larger positive impact on post-release for women than for men (Brewster \& Sharp, 2002).

Olson et al. (2016) included measures of both violent and general recidivism (rearrest for a violent or general crime) in their analysis of gender and recidivism. In terms of general recidivism they found that prior arrest for non-domestic violent crimes was predictive for both men and women but stronger for women. In contrast, prior arrest for drug possession (rather than sales) likewise was a correlate for both genders but stronger for men. However, when examining violent recidivism, they found that prior arrests for non-violent crimes and prior arrests for drug selling was associated with higher rates of recidivism for women but not predictive for men. Yet 
prior arrests for drug possession predicted lower violent recidivism for men but was not significant for women (Olson et al., 2016)

Additional research has also looked at sentence type and lengths' impact on recidivism. Collins (2010) conducted a meta-analysis of the effect of gender on violent and non-violent recidivism. Collins (2010) looked at indicators of criminal history rather than type of offense and found that criminal history (violent and nonviolent) most consistently predicted violent recidivism but that it was homogeneous across gender. Criminals who recidivated violently had more extensive criminal histories in both violent and non-violent crime. Yet some gender differences were observed. In men, increased violent criminal history was associated with increased violent recidivism but this was not true for women. However longer sentences were predictive of violent reoffending for women but not men. In fact, sentence length was the only significant gender difference between violent recidivists and non-recidivists (Collins, 2010).

Olson et al. (2016) found that for women who commit violent crimes, marriage is associated with lower recidivism but that this is not true for men. McCoy and Miller (2013) noted that when initially convicted of property offenses, men were more likely to recidivate than women. Jones and Sims (1997) observed that when men and women were both released under extensive probation supervision, men were more likely to be rearrested than women. Huebner and Pleggenkuhle (2015) also noted gender differences in the types of sentences and their impact on recidivism. They found that men who were serving time for personal or property crimes were likely to recidivate sooner than those sentenced for drug crimes, but characterizations of criminal offense were not significant among women.

Overall among risk factors, some gender differences are seen when looking at the impact of the importation variables age and gang membership. However, once again other research regarding race/ethnicity shows mixed results. Most importantly, very little previous research has examined whether the risk factor correlates of homelessness and gang membership in particular are gendered in their impact on reoffending (see Fedock et al., 2013; Jones and Sims, 1997; Lauderdale and Burman, 2009; Mears et al., 2016). This study looks at the correlates of protective and risk factors on recidivism separately for men and women while using protective and risk factors to consider whether the importation or deprivation model of prison has more support for recidivism. 


\section{Data and Methods}

\subsection{Data and Cases}

The data is provided by the Department of Corrections of a large western state in the USA. It looks at inmates who entered or re-entered prison between 2009 and 2011. It is a once in time snapshot and cross-sectional. The enumeration includes 6,674 females $(17.3 \%)$ and 31,842 males $(82.7 \%)$. Data was collected by the Department of Corrections on demographic information such as race/ethnicity, gender, age, education, type of offense, sentence length, and repeat incarceration ${ }^{3}$.

\subsection{Dependent Measure}

As a society, we are concerned whether prison works to stop offending. A measure of continued offending is whether an individual returns to prison after release. While time between repeat incarceration cannot be determined, it is measured by a "yes" or "no" dummy variable that compares an individual's first admission to prison to those for whom prison is a readmission ${ }^{4}$. Further, separate analyses are run for men and women.

\subsection{Independent Measures}

\subsubsection{Protective Factors.}

Education Education is measured by a dummy variable comparing those with a high school degree before incarceration to those with no high school degree as the reference category.

Programming Initial classification in this large western state puts inmates into internal programs that are deemed necessary to help each individual become a lawabiding citizen upon release. Whether or not inmates were involved in three prison programs was documented: Family relations, offender change, and chemical treatment ${ }^{5}$. The family relations program focuses on improving the inmates' relationship with their families and children in particular. The offender change program has many components, most notably moral reconation therapy (MRT) and

3 The state level has become the standard unit of analysis for prison research as most inmates are housed in state institutions (Heimer et al., 2012).

4 As the focus is violence committed while incarcerated, no other type of sentence (i.e., probation and community corrections) are considered in the repeat incarceration variable.

5 There is no information on how long the individual was in a program, just whether they were enrolled. This is further discussed in the limitations section. 
stress and anger management (SAM). The goal of MRT is to improve pro-social reasoning and behaviors among inmates, while SAM creates an understanding of anger and stress triggers and provides tools to channel this anger/stress in non-violent ways. The chemical treatment program focuses on an inmates' substance use such as addiction to alcohol and/or drugs.

Visitors Visitation is used as a proxy for community ties outside prison. Each prison facility in the state has different regulations on the number of visitors per visit. However, the maximum number of visitors per visit in any facility is ten. This research uses overall number of visitors as a proxy for visitation. Thus, rather than just considering whether an inmate has a visitor or not, how many visitors they had is considered. Based on the frequency distribution for visitation, four categories of coding were created for those with less than ten visitors, eleven to one hundred, one hundred one to five hundred, and over five hundred visitors.

However, an inmate who has served a shorter sentence and has the same number of visitors as one with a longer sentence arguably has more social ties. Thus, the number of visitors is standardized by sentence length through the creation of $\mathrm{z}$ scores to make comparisons between these different groups.

Relationship Status Relationship status can differentially impact male and female recidivism as women with stronger social bonds in the form of social ties to intimate partners have a lower risk of recidivism (Cobbina et al., 2012). As a result, three dummy variables are used to determine whether the inmate is divorced, married, or single.

\subsubsection{Risk Factors.}

Race/ethnicity Race/ethnicity is measured with six dummy variables for Asian/ Pacific Islander, Black, Latinx, Native American, Other, and White with Whites as the reference category. This data allows for a robust consideration of race/ethnicity.

Age Age is perhaps one of the strongest correlates of prison recidivism. Age is divided into three categories: 18-29, 30-49, and 50 plus with 50 plus as the reference category.

Homelessness This large western state documents whether inmates had a place of residence before incarceration or whether they were homeless. This dummy variable compares those who were homeless before incarceration to those who were not, with not being homeless as the reference category. 
Prison conduct Scholarship has documented potential implications of in-prison experiences for prison recidivism (Huebner et al., 2007). Cochran et al. (2014) found that inmates who engaged in prison misconduct (violent in particular), were more likely to recidivate. Two dummy variable measures of misconduct are included: violent and nonviolent. Using official report data, the infractions that the state identify as violent are listed in Appendix A.

Gang membership While gang membership is less common among females (see Lauderdale \& Burman, 2009), gang members are at greater risk for recidivism (see Dooley et al., 2014; Huebner et al., 2007). As a result, a dummy variable for gang membership is included with no gang membership as the reference category. Gang membership in this western state was determined by voluntary admission from the inmate or assessment by a corrections officer.

Sentence length Again, taking research from the literature review into account and the frequency distribution of sentences imposed, sentence length is classified into four categories: less than one year, one to just less than two years, two to just less than three years, and more than three years ${ }^{6}$.

\subsection{Control Variable}

All offenses for which the inmate is currently incarcerated are classified into one of three categories: violent offense, property offense, or drug offense. Prior incarceration for any type of offense is controlled with repeat incarceration.

\subsection{Analytical Strategy}

Initial descriptive and bivariate analysis were conducted before regressions were run. This initial analysis considered percentages and relative odds of the protective and risk factor correlates on reoffending using separate models for males and females. Binomial logistic regression (as the dependent measure is dichotomous) was then used to consider the effect of protective and risk factors on prison recidivism by gender? Further, before conducting analyses, a variation inflation factor (VIF) test was employed on all variables to check for multicollinearity. No VIF above 4 was found (the standard cut off level), indicating that multicollinearity was not a problem in this study.

6 The control of 3 or more years as a grouping was chosen based on frequency as very few lengthy sentences were included in the study.

7 Missing data was extremely small and random. As a result, list wise deletion of missing values was used in the statistical analysis. 


\section{Analysis}

\subsection{Descriptive and Bivariate Analysis}

Separate tables were created for males and females showing percentages and relative odds of those who did and did not recidivate. In analyses run separately, the largest similar correlate on males and females who had recidivated were the preprison variables of education, gang membership, and homelessness and the extraprison variable of visitation. Alternatively, the largest differential impact was seen within prison through programming and the extra-prison variable relationship status as correlates of recidivism.

Table 1. Descriptive Analysis of protective factors (education, programming, community ties, relationship status) and risk factors (race/ethnicity, age, homelessness, prison conduct, gang membership, sentence length) on recidivism for males $(\mathrm{N}=\mathbf{3 1 , 8 4 2})$

\begin{tabular}{|c|c|c|c|c|}
\hline & No Repeat $(\%)$ & Yes Repeat $(\%)$ & Total $(N)$ & $\underline{\text { Relative Odds }}$ \\
\hline \multicolumn{5}{|l|}{ Education } \\
\hline High School Degree - Yes & 81.4 & 18.6 & 30,133 & 0.55 \\
\hline High School Degree - No ${ }^{a}$ & 70.5 & 29.5 & 1,709 & 1.00 \\
\hline \multicolumn{5}{|l|}{ Programming } \\
\hline Family Relations & 55.9 & 44.1 & 4,846 & 0.95 \\
\hline Offender Change & 59.0 & 41.0 & 13,399 & 0.84 \\
\hline Chemical Treatment $^{\mathrm{a}}$ & 54.6 & 45.4 & 7,549 & 1.00 \\
\hline \multicolumn{5}{|l|}{ Visitors $^{\mathrm{b}}$} \\
\hline Less than Ten & 60.6 & 39.4 & 6,011 & 1.46 \\
\hline Eleven to One Hundred & 64.0 & 36.0 & 3,170 & 1.26 \\
\hline One Hundred One to Five Hundred ${ }^{a}$ & 69.1 & 30.9 & 434 & 1.00 \\
\hline \multicolumn{5}{|l|}{ Race/Ethnicity } \\
\hline White $^{\mathrm{a}}$ & 83.2 & 16.8 & 22,401 & 1.00 \\
\hline Asian/Pacific Islander & 85.4 & 14.6 & 1,035 & 0.85 \\
\hline Black & 73.3 & 26.7 & 5,238 & 1.80 \\
\hline Latinx & 69.0 & 31.0 & \begin{tabular}{|l|}
1,602 \\
\end{tabular} & 2.22 \\
\hline Native American & 69.4 & 30.6 & 973 & 2.19 \\
\hline \multicolumn{5}{|l|}{ Age } \\
\hline $18-29$ & 95.0 & 5.0 & 7,269 & 0.16 \\
\hline $30-49$ & 76.2 & 23.8 & 16,592 & 0.97 \\
\hline $50+^{\mathrm{a}}$ & 75.5 & 24.5 & 6,037 & 1.00 \\
\hline \multicolumn{5}{|l|}{ Relationship Status } \\
\hline Divorced & 73.2 & 26.8 & 910 & 0.51 \\
\hline Married & 72.7 & 27.3 & 1,211 & 0.52 \\
\hline Single $^{a}$ & 58.3 & 41.7 & 9,409 & 1.00 \\
\hline \multicolumn{5}{|l|}{ Gang Membership } \\
\hline Gang - Yes & 50.1 & 49.9 & 1,020 & 4.48 \\
\hline Gang - $\mathrm{No}^{\mathrm{a}}$ & 81.8 & 18.2 & 30,822 & 1.00 \\
\hline Homelessness & & & & \\
\hline
\end{tabular}




\begin{tabular}{|c|c|c|c|c|}
\hline Homeless - Yes & 71.8 & 28.2 & 2,802 & 1.74 \\
\hline Homeless - $\mathrm{No}^{\text {a }}$ & 81.6 & 18.4 & 29,040 & 1.00 \\
\hline \multicolumn{5}{|l|}{ Prison Conduct } \\
\hline Non Violent Infraction & 53.1 & 46.9 & 7,877 & 0.85 \\
\hline Violent Infraction $^{\text {a }}$ & 48.9 & 51.1 & 2,016 & 1.00 \\
\hline \multicolumn{5}{|l|}{ Sentence Length } \\
\hline Less than One Year ${ }^{\mathrm{a}}$ & 81.0 & 19.0 & 22,090 & 1.00 \\
\hline One to Two Years & 81.6 & 18.4 & 8,640 & 0.96 \\
\hline Two to Three Years & 69.7 & 30.3 & 2,971 & 1.85 \\
\hline More than Three Years & 76.0 & 24.0 & 796 & 1.35 \\
\hline
\end{tabular}

${ }^{\text {a }}$ Relative odds reference category

${ }^{\mathrm{b}}$ Visitors is standardized

Both males and females with a high school degree were only approximately half as likely to recidivate as those without ( 0.55 for males and 0.40 for females). However, having less visitors, being Latinx, in a gang, and homeless were all correlated with greater recidivism for both males and females. Similarly, for both men and women, those with less than one hundred visitors were correlated to greater recidivism, as were those in a gang (4.48 times for men and 6.71 times for women) and those homeless (1.74 times for men and 1.73 times for women). Interestingly, Latinx females were 6.52 times more likely to recidivate in comparison to White females.

Table 2. Descriptive Analysis of protective factors (education, programming, community ties, relationship status) and risk factors (race/ethnicity, age, homelessness, prison conduct, gang membership, sentence length) on recidivism for females $(\mathrm{N}=6,674)$

\begin{tabular}{|c|c|c|c|c|}
\hline & No Repeat (\%) & Yes Repeat (\%) & Total $(N)$ & Relative Odds \\
\hline \multicolumn{5}{|l|}{ Education } \\
\hline High School Degree - Yes & 89.7 & 10.3 & 6,459 & 0.40 \\
\hline High School Degree - No ${ }^{a}$ & 77.7 & 22.3 & 215 & 1.00 \\
\hline \multicolumn{5}{|l|}{ Programming } \\
\hline Family Relations & 63.9 & 36.1 & 1,029 & 1.23 \\
\hline Offender Change & 68.4 & 31.6 & 2,120 & 1.01 \\
\hline Chemical Treatment $^{\mathrm{a}}$ & 68.6 & 31.4 & 1,703 & 1.00 \\
\hline \multicolumn{5}{|l|}{ Visitors $^{\mathrm{b}}$} \\
\hline Less than Ten & 65.4 & 34.6 & 911 & 2.64 \\
\hline Eleven to One Hundred & 68.7 & 31.3 & 505 & 2.28 \\
\hline One Hundred One to Five Hundred ${ }^{a}$ & 83.3 & 16.7 & 60 & 1.00 \\
\hline \multicolumn{5}{|l|}{ Race/Ethnicity } \\
\hline White $^{\mathrm{a}}$ & 90.9 & 9.1 & 5,151 & 1.00 \\
\hline Asian/Pacific Islander & 94.3 & 5.7 & 174 & 0.61 \\
\hline Black & 84.4 & 15.6 & 737 & 1.84 \\
\hline Latinx & 60.4 & 39.6 & 187 & 6.52 \\
\hline Native American & 86.3 & 13.7 & 293 & 1.57 \\
\hline \multicolumn{5}{|l|}{ Age } \\
\hline $18-29$ & 97.4 & 2.6 & 1,432 & 0.17 \\
\hline
\end{tabular}




\begin{tabular}{|c|c|c|c|c|}
\hline $30-49$ & 86.7 & 13.3 & 3,705 & 0.97 \\
\hline $50+{ }^{a}$ & 86.4 & 13.6 & 1,133 & 1.00 \\
\hline \multicolumn{5}{|l|}{ Relationship Status } \\
\hline Divorced & 77.2 & 22.8 & 558 & 1.19 \\
\hline Married & 77.2 & 22.8 & 482 & 1.20 \\
\hline Single $^{\mathrm{a}}$ & 80.2 & 19.8 & 1,661 & 1.00 \\
\hline \multicolumn{5}{|l|}{ Gang Membership } \\
\hline Gang - Yes & 55.6 & 44.4 & 9 & 6.71 \\
\hline Gang - $\mathrm{No}^{\mathrm{a}}$ & 89.3 & 10.7 & 6,665 & 1.00 \\
\hline \multicolumn{5}{|l|}{ Homelessness } \\
\hline Homeless - Yes & 83.3 & 16.7 & 323 & 1.73 \\
\hline Homeless - $\mathrm{No}^{\mathrm{a}}$ & 89.6 & 10.4 & 6,351 & 1.00 \\
\hline \multicolumn{5}{|l|}{ Prison Conduct } \\
\hline Non Violent Infraction & 63.5 & 36.5 & 1,238 & 0.87 \\
\hline Violent Infraction $^{\mathrm{a}}$ & 60.1 & 39.9 & 286 & 1.00 \\
\hline \multicolumn{5}{|l|}{ Sentence Length } \\
\hline Less than One Year ${ }^{\mathrm{a}}$ & 89.2 & 10.8 & 5,399 & 1.00 \\
\hline One to Two Years & 89.7 & 10.3 & 1,389 & 0.95 \\
\hline Two to Three Years & 72.7 & 27.3 & 242 & 3.09 \\
\hline More than Three Years & 79.8 & 20.2 & 119 & 2.08 \\
\hline
\end{tabular}

${ }^{\text {a }}$ Relative odds reference category

${ }^{\mathrm{b}}$ Visitors is standardized

Two areas of difference found between males and females were the correlates of programming and relationship status to recidivism. In comparison to the chemical treatment program, men were less likely to recidivate if involved in the family relations ( 0.95 times) or offender change program (0.84 times). However, compared to the chemical treatment program, women were more likely to recidivate if involved in the family relations (1.23 times) or offender change (1.01 times). This suggests the chemical treatment program works more effectively with female recidivism than male recidivism. Compared to single males, those married and divorced were less likely to recidivate ( 0.52 and 0.51 times respectively). However, compared to single women, those married and divorced were more likely to recidivate (1.20 and 1.19 times respectively). Previous research has also found that there exists a gendered impact of relationship status on recidivism (see Benda, 2005; Cobbina et al., 2012; Taylor, 2015).

\subsection{Multivariate Analysis}

The results of multivariate analysis are presented in Table 3 . The protective factors of education, community ties, and relationship status had a positive impact on recidivism for males, while programming did not. Males $(\mathrm{OR}=0.84, \mathrm{p}<.05)$ with a 
high school degree were less likely to recidivate than those without. Similarly, males with more visitations were less likely to recidivate and males who were divorced were less likely to recidivate $(\mathrm{OR}=0.22, \mathrm{p}<.001)$. Interestingly, men who were married were also less likely to recidivate $(\mathrm{OR}=0.23, \mathrm{p}<.01)$. This indicates support for Laub and Sampson's (2003) study that most men who desisted from crime had long-term stability in marriage.

Similarly, among women, education had a stronger positive impact on reducing recidivism than for men $(\mathrm{OR}=0.47, \mathrm{p}<.001)$. Women who were divorced were less likely to recidivate $(\mathrm{OR}=.36, \mathrm{p}<.01)$. This furthers support for research claiming that women are more likely to offend under the influence of the men in their lives.

Surprisingly, male and female offenders in all programming were more likely to recidivate. As this large western state identifies those with the greatest need for mandatory programming, perhaps this indicates they correctly identify offenders. However, it also does not show much support for prison programming. Perhaps this also provides support for a call for more use of gender-specific programming to reduce recidivism. A call for more gender-specific programming will be given in the discussion.

Not surprisingly, risk factors of race/ethnicity, age, prison conduct, and length of sentence all significantly contributed to recidivating. Black and Latinx males and females were more likely to recidivate than White males and females respectively. Native American males were also more likely to recidivate than White males $(\mathrm{OR}=1.56, \mathrm{p}<.001)$. Both males and females with nonviolent infractions in prison were more likely to recidivate $(\mathrm{OR}=3.35, \mathrm{p}<.001$ and $\mathrm{OR}=2.15, \mathrm{p}<.001$ respectively). For males this extended to those who also committed a violent infraction $(\mathrm{OR}=1.93$, $\mathrm{p}<.001)$. Both males and females who served shorter sentences of less than one year were more likely to recidivate $(\mathrm{OR}=1.64, \mathrm{p}<.001$ and $\mathrm{OR}=1.71, \mathrm{p}<.01$ respectively $)$.

Two unique risk factors that this research assesses for both men and women were gang membership and prior homelessness. Not surprisingly, gang membership increased the risk of recidivism for men $(\mathrm{OR}=2.06, \mathrm{p}<.001)$. However, it was also correlated with increased recidivism for women. Finally, homelessness was correlated with increased odds of recidivism for both men and women $(\mathrm{OR}=1.22, \mathrm{p}<.01$ and $\mathrm{OR}=1.72, \mathrm{p}<.05$ respectively). 
Table 3. Logistic Regression of protective factors (education, programming, community ties, relationship status) and risk factors (race/ethnicity, age, homelessness, prison conduct, gang membership, sentence length) on differences in recidivism by gender $(\mathrm{N}=\mathbf{3 8 , 5 1 6})$

\begin{tabular}{|c|c|c|c|c|}
\hline & \multicolumn{2}{|l|}{ Male } & \multicolumn{2}{|l|}{ Female } \\
\hline & $\underline{B}^{\mathrm{a}}$ & Odds & $\underline{B}^{\mathrm{a}}$ & Odds \\
\hline High School Degree $^{b}$ & $-0.17 *(0.07)$ & 0.84 & $-0.75 * * *(0.20)$ & 0.47 \\
\hline \multicolumn{5}{|l|}{ Programming } \\
\hline Family Relations & $0.34 * * *(0.05)$ & 1.40 & $0.34 * *(0.12)$ & 1.40 \\
\hline Offender Change & $1.80 * * *(0.05)$ & 6.07 & $2.53 * * *(0.18)$ & 12.57 \\
\hline Chemical Treatment & $1.07 * * *(0.04)$ & 2.90 & $1.15 * * *(0.12)$ & 3.15 \\
\hline \multicolumn{5}{|l|}{ Visitors $\left(\right.$ Standardized) $^{\mathrm{c}}$} \\
\hline Less than Ten & $0.18 * * *(0.02)$ & 1.20 & $0.14 *(0.06)$ & 1.15 \\
\hline Eleven to One Hundred & $-0.12 * * *(0.02)$ & 0.89 & $-0.06(0.05)$ & 0.94 \\
\hline One Hundred One to Five Hundred & $-0.05 * *(0.02)$ & 0.95 & $-0.04(0.05)$ & 0.96 \\
\hline \multicolumn{5}{|l|}{ Race/Ethnicity ${ }^{\mathrm{d}}$} \\
\hline Asian/Pacific Islander & $0.10(0.12)$ & 1.11 & $-0.28(0.41)$ & 0.76 \\
\hline Black & $0.32 * * *(0.05)$ & 1.37 & $0.74 * * *(0.16)$ & 2.09 \\
\hline Latinx & $0.37 * * *(0.08)$ & 1.45 & $1.17 * * *(0.21)$ & 3.21 \\
\hline Native American & $0.45 * * *(0.10)$ & 1.56 & $-0.09(0.24)$ & 0.92 \\
\hline Other & $-1.26 * * *(0.31)$ & 0.29 & $-1.08 *(0.51)$ & 0.34 \\
\hline Age $^{\mathrm{e}}$ & $0.74 * * *(0.04)$ & 2.10 & $0.66^{* * *}(0.10)$ & 1.93 \\
\hline \multicolumn{5}{|l|}{ Relationship Status } \\
\hline Divorced & $-1.54 * * *(0.41)$ & 0.22 & $-1.03 *(0.43)$ & 0.36 \\
\hline Married & $-1.48 * *(0.53)$ & 0.23 & $-1.52(1.14)$ & 0.22 \\
\hline Single & $-0.35(0.44)$ & 0.70 & $0.67(0.46)$ & 1.95 \\
\hline Gang Membership $^{f}$ & $0.72 * * *(0.09)$ & 2.06 & $2.23 *(0.98)$ & 9.29 \\
\hline Homelessness $^{\mathrm{g}}$ & $0.20 * *(0.06)$ & 1.22 & $0.54 *(0.21)$ & 1.72 \\
\hline \multicolumn{5}{|l|}{ Prison Conduct } \\
\hline Non Violent Infraction & $1.21 * * *(0.04)$ & 3.35 & $0.77 * * *(0.12)$ & 2.15 \\
\hline Violent Infraction & $0.66 * * *(0.07)$ & 1.93 & $0.29(0.17)$ & 1.34 \\
\hline \multicolumn{5}{|l|}{ Sentence Length } \\
\hline Less than One Year & $0.49 * * *(0.07)$ & 1.64 & $0.53 * *(0.20)$ & 1.71 \\
\hline One to Less than Two Years & $-0.07(0.07)$ & 0.93 & $-0.20(0.17)$ & 0.82 \\
\hline Two to Less than Three Years & $0.02(0.08)$ & 1.02 & $0.06(0.22)$ & 1.07 \\
\hline More than Three Years & $0.19(0.13)$ & 1.21 & $0.46(0.35)$ & 1.58 \\
\hline \multicolumn{5}{|l|}{ Control Variables } \\
\hline Violent Offense & $-0.02(0.05)$ & 0.98 & $-0.23(0.17)$ & 0.79 \\
\hline Property Offense & $0.35 * * *(0.04)$ & 1.42 & $0.14(0.12)$ & 1.15 \\
\hline Drug Offense & $0.10 *(0.05)$ & 1.10 & $-0.06(0.12)$ & 0.94 \\
\hline
\end{tabular}

\footnotetext{
a Standard Errors in Parentheses

b No High School Degree Reference

c Visitors is Standardized

${ }^{d}$ White Reference

e Age 50+ Reference Category

${ }^{\mathrm{f}}$ No Gang Membership Reference Category

${ }^{\mathrm{g}}$ No Homeless Reference

$* \mathrm{p}<.05, * * \mathrm{p}<.01, * * * \mathrm{p}<.001$
} 


\section{Discussion}

The limited research literature on gender effects of protective and risk factors on recidivism is largely mixed. The results of this study regarding gender were mixed as well but do provide consistent support for the importation model of prison adaptation. Findings regarding the deprivation model were mixed. All pre-prison indicators (education, age, race/ethnicity, homelessness and gang membership) were predictive of recidivism. Both extra-prison indicators (community ties and relationship status) were likewise predictive of recidivism. These findings support the importation model. This furthers Thomas and Foster's (1973) critique of the deprivation model's limitation by assuming the prison to be a closed system and failing to account for pre and extra-prison factors.

The deprivation model related findings regarding the within-prison indicators (programming, prison conduct and sentence length) were inconsistent. Programming was found to be significantly associated with increased recidivism. Prison conduct was associated with recidivism, which is consistent with a deprivation model prediction, but sentence length was not. The effects of the various factors associated with deprivation would presumably be greater the longer the inmate was incarcerated. These findings show that shorter sentence lengths were significantly predictive of a higher likelihood of recidivism while longer sentences were not. This not only contradicts the prediction of the deprivation explanation but could also lend further support for the importation model. The effect of pre and extra-prison experiences may outweigh within-prison effects.

When assessing protective and risk factors with respect to gender, three gender specific correlates of recidivism were found to be significantly associated with recidivism for men only (committing a violent infraction in prison and being Native American was tied to increased recidivism and being married was associated with decreased recidivism). The effects of marital status on recidivism are mixed. Cobbina et al. (2012) found it to be a stronger protective factor for men and Taylor (2015) reported that women living with an intimate partner were more likely to recidivate. The current findings are somewhat consistent with both as marital status was found to be a correlate of recidivism for men and being divorced was associated with less recidivism for both men and women. 
The research on race/ethnicity as a correlate of recidivism was also found to be mixed with some research determining race/ethnicity as significant (Olsen et al., 2016) and even gender specific predicting men's recidivism but not women's (Cobbina et al., 2012). Yet McCoy and Miller (2013) determined race/ethnicity was not a significant correlate for either women or men. The current study finds race/ ethnicity to be a significant correlate for both genders (Black and Latinx) but being Native American was predictive for men only.

No gender specific correlates were found to be significantly associated with higher recidivism for women. Although among those correlates which were significant for both, four were stronger for one gender. Low visitation $(<10)$, being divorced and being a gang member were significant for both but stronger for men. The closest to a gender specific correlate for women was having a high school diploma but this was also true for men, albeit less so. These findings are consistent with Collins' (2010) meta-analysis finding that the protective effect of the education level of inmates was homogeneous across gender. The differential impact of a high school degree on women more so than men supports Huebner and Pleggenkuhle's (2015) finding that possessing a high school diploma was predictive of being less likely to recidivate in a female sample. Much research suggests the importance of education in reducing recidivism particularly among females, and this research would support such a call.

Not surprisingly, the risk factors of age and homelessness were significant correlates for both men and women as were short sentences and having committed a non-violent infraction in prison. What was surprising in this study was that the protective factor of being involved in programming was associated with higher recidivism for both genders. This was true for all three categories of programming (family relations, offender change and chemical treatment). That programming might fail to predict lowered recidivism would not be surprising but predicting higher recidivism is contrary to the literature and expectations.

In this large western state in the USA programming is mandatory for those inmates identified with the greatest need. While the outcome of programming on the goal of lowering recidivism is not supported in this study, it is likely that those with the greatest needs (and issues associated with future recidivism) are being correctly identified. It should be noted that the Department of Corrections in this state has implemented offender change projects in its system after this data was recorded and 
has shown success in lowering the incidence of involvement in violent infractions of those who completed the program. Such programming may also lower the likelihood of recidivism and future research is needed to determine if that is the case.

Further, there has been a call for gender-specific programming (see Bloom \& Covington, 1998; Foley, 2008; Morash et al., 1998; Wright et al., 2012). Certainly, if current programming is not showing a reduction in recidivism, then gender-specific programming might be a better option. For example, an argument has been made for increased prison programming to maintain contact between incarcerated women and their children and to improve drug and alcohol programs for women.

\subsection{Limitations and Future Research}

This research sought to determine if some correlates of recidivism were gender specific and, if so, which ones. It further compared the importation and deprivation models of prison and found some support for the importation model. It found that the literature on gender specific correlates of recidivism was limited and that there was little consistency in the findings. This research contributes to further developing that literature and found that there are some correlates of recidivism that were gender specific, but that they predicted higher recidivism for men and not for women. It was also noted that there was a differential impact of the protective factor of education on recidivism for women more so that for men. Collins' meta-analysis (2010) noted that the foremost gap in current knowledge of recidivism was that there was not enough data on women. Several studies have been done since her recognition of the dearth of research on women and recidivism and some, reviewed here, have looked at women as a separate and unique population. This is an area of growing interest and importance and much more work needs to be done.

Further, time between repeat incarceration cannot be assessed and no causal time ordering can be drawn from our findings, as they are a one-time snapshot of whether the inmate entered prison for the first time or as a repeat incarceration between 2009 and 2011. As such, our findings on the effects of internal prison programming are difficult to assess. It would be necessary to know whether the incidence of violence occurred prior to, during, or after participation to know whether the programs are working or could be more effective if changed. This would certainly be important to assess when calling for more gender-specific programming in prison.

Grant Support: Authors received no financial support for this work. 


\section{References}

Bales, W. \& Mears, D. (2008). Inmate social ties and the transition to society: does visitation reduce recidivism? Journal of Research in Crime and Delinquency, 45, 287-321.

Baradon, T., Fonagy, P., Kata, L., Sleed, M. (2008). New beginnings: an experienced-based programme addressing the attachment relationship between mothers and their babies in prison. Journal of Child Psychotherapy, 34(2), 240-258.

Barrick, K., Lattimore, P., \& Visher, C. (2014). Reentering women: the impact of social ties on long-term recidivism. The Prison Journal, 94(3), 279-304.

Bayse, D., Allgood, S., \& Van Wyk, P. (1991). Family life education: an effective tool for prisoner rehabilitation. Family Relations, 40(3), 245-257.

Belknap, J. (1996). The invisible woman: gender, crime, and justice. Belmont, CA, Wadsworth.

Benda, B. (2005). Gender differences in life-course theory of recidivism: a survival analysis. International Journal of Offender Therapy and Comparative Criminology, 49(3), 325-342.

Berg, M. \& Huebner, B. (2010). Reentry and the ties that bind: an examination of socialties, employment, and recidivism. Justice Quarterly, 28(2), 382-410.

Bloom, B. \& Covington, S. (1998) Gender specific programming for female offenders: what is it and why is it important? Paper presented at the $50^{\text {th }}$ annual meeting of the American Society of Criminology, Washington, DC.

Brewster, D. \& Sharp, S. (2002). Educational programs and recidivism in Oklahoma: another look. The Prison Journal, 82(3), 314-334.

Calhoun, S., Messina, N., Cartier, J., \& Torres, S. (2010). Implementing gender-responsive treatment for women in prison: client and staff perspectives. Federal Probation, 74(3), 27-33.

Cao, L., Zhao, J., \& Van Dine S. (1997). Prison disciplinary tickets: a test of the deprivation and importation models. Journal of Criminal Justice, 25(2), 103-113.

Casey-Acevedo, K., Bakken, T., \& Karle, A. (2004). Children visiting mothers in prison: the effect on mothers behavior and Disciplinary Adjustment. Australian and New Zealand Journal of Criminology, 37, 418-430.

Cobbina, J., Huebner, B., \& Berg, M. (2012). Men, women, and post release offending: an examination of the nature of the link between relational ties and recidivism. Crime \& Delinquency, 58(3), 331-361.

Cochran, J., Mears, D., Bales, W., \& Stewart, E. (2014). Does inmate behavior affect post-release offending? Investigating the misconduct-recidivism relationship among youth and adults. Justice Quarterly 31(6), 1044-1073.

Collins, R. (2010). The effect of gender on violent and nonviolent recidivism: a meta-analysis. Journal of Criminal Justice, 38, 675-684.

Davis, S. (1985). Recidivism among offenders released from incarceration in 1982. Oklahoma City: Oklahoma Department of Corrections

Dooley, B., Seals, A., \& Skarbek, D. (2014). The effect of prison gang membership on recidivism. Journal of Criminal Justice, 42(3), 267-275.

Education Services Newsletter. (2009). Issue II. NDOC. Web. Spring, 2009: 2-3.

Esperian, J. (2010). The effect of prison education programs on recidivism. The Journal of Correctional Education, 61(4), 316-334.

Fedock, G., Fries, L., \& Kubiak S. (2013). Service needs for incarcerated adults: exploring gender differences, Journal of Offender Rehabilitation, 52, 493-508.

Foley, A. (2008). The current state of gender-specific delinquency programming. Journal of Criminal Justice, $36(3), 262-269$.

French, S. A. \& Gendreau, P. (2006). Reducing Prison Misconducts: What Works! Criminal Justice and Behavior, 33(2), 185-218. 
Gerber, J., \& Fritsch, E. (1995). Adult academic and vocational correctional education programs: a review of recent research. Journal of Offender Rehabilitation, 22, 199-242.

Harer, M. D. (1995). Recidivism among federal prisoners released in 1987. Journal of Correctional Education, 46(3), 98-128.

Hirschi, T. (1969). Causes of Delinquency. Berkeley: University of California Press.

Holt, N. \& Miller, D. (1971). Explorations in Inmate-Family Relationships. Sacramento: Research Division, Department of Corrections, State of California (http://www.fcnetwork.org/reading/holt-miller/holt-miller8. html)

Huebner, B., DeJong, C., \& Cobbina, J. (2010). Women coming home: long-term patterns of recidivism. Justice Quarterly, 27(2), 225-254.

Huebner, B. \& Pleggenkuhle, B. (2015). Residential location, household, composition, and recidivism: an analysis by gender. Justice Quarterly, 32(5): 818-844.

Huebner, B., Varano, S., \& Bynum, T. (2007). Gangs, guns, and drugs: recidivism among serious, young offenders. Criminology \& Public Policy, 6(2), 187-221.

Jancic, M. (1998). Does correctional education have an effect on recidivism? Journal of Correctional Education, 49(4), 152-161.

Jones, M. \& Sims, B. (1997). Recidivism of offenders released from prison in North Carolina: a gender comparison. The Prison Journal 77(3), 335-348.

Jurik, N. (1983). The economics of female recidivism. Criminology, 21(4), 603-622.

Karp, D. (2010). Unlocking me, unmasking masculinities: doing men's work in prison. The Journal of Men's Studies, 18(1), 63-83.

Keyes, D. (1996). Preventing Prison Misconduct Behavior: A Quantitative Review of the Literature. Unpublished Honor's Thesis. Saint John, Canada: University of New Brunswick.

Laub, J. \& Sampson, R. (2003). Shared Beginnings, Divergent Lives: Delinquent Boys to Age 70. Cambridge, MA, Harvard University Press.

Lauderdale, M. \& Burman, M. (2009). Contemporary patterns of female gangs in correctional settings. Journal of Human Behavior in the Social Environment, 19(3), 258-280.

Makarios, M., Steiner, B., \& Travis, L. (2010). Examining the correlates of recidivism among men and women released from prison in Ohio. Criminal Justice and Behavior, 37(12), 1377-1391.

Martinson, R. (1974). What works? Questions and answers about prison reform. The Public Interest, $22-54$.

Mills, J., Kroner, D., \& Hemmati, T. (2003). Predicting violent behavior through a static-stable variable. Journal of Interpersonal Violence, 18(8): 891-904.

Mitchell, M., Spooner, K., Jai, D., \& Zhang Y. (2016). The effect of prison visitation on reentry success: a metaanalysis. Journal of Criminal Justice, 47, 74-83.

McCoy, L. \& Miller, H. (2013). Comparing gender across risk and recidivism in nonviolent offenders. Women \& Criminal Justice, 23(2), 143-162.

Mears, D., Cochran, J., Bales, W., \& Bhati, A. (2016). Recidivism and time served in prison. Journal of Criminal Law \& Criminology, 106(1), 83-124.

Minnesota Department of Corrections. (2011). The Effects of Prison Visitation on Offender Recidivism. St. Paul, $\mathrm{MN}$ : Minnesota Department of Corrections.

Morash, M., Bynum, T., \& Koons, B. (1998). Women offenders: programming needs and promising approaches. Washington, DC: National Institute of Justice.

Morgan, R. \& Flora, D. (2002). Group psychotherapy with incarcerated offenders: a research synthesis. Group Dynamics, 6, 203-218.

Olson, D., Stalans, L., and Escobar, G. (2016). Comparing male and female prison releasees across risk factors and post-prison recidivism. Women \& Criminal Justice, 26(2), 122-144. 
Phelps, M. (2011). Rehabilitation in the punitive era: the gap between rhetoric and reality in U.S. prison programs. Law and Society Review, 45(1): 33-68.

Piehl, A. (1998). Economic conditions, work, and crime. In M. Tonry (Ed.), The handbook of crime and punishment (pp. 302-319). New York: Oxford University Press.

Ryan, J., \& Yang, H. (2005). Family contact and recidivism: a longitudinal study of adjudicated delinquents in residential care. Social Work Research, 29, 31-39.

Schafer, N. (1994). Exploring the link between visits and parole success: a survey of prison visitors". International Journal of Offender Therapy and Comparative Criminology (38)1, 17-32.

Scott, C., Grella, C., Dennis, M., \& Funk, R. (2014). Correlates of recidivism over 3 years among substanceusing women released from jail. Criminal Justice \& Behavior, 41(11), 1257-1289.

Scott, T. \& Ruddell, R. (2011). Canadian female gang inmates: risk, needs, and the potential for prison rehabilitation. Journal of Offender Rehabilitation, 50(6), 305-326.

Solinas-Saunders, M. \& Stacer, M. (2017). A retrospective analysis of repeated incarceration using a national sample: what makes female inmates different to male inmates? Victims \& Offenders, 12(1), 138-173.

Stuart, B. \& Brice-Baker, J. (2004). Correlates of higher rates of recidivism in female prisoners: an exploratory study. The Journal of Psychiatry \& Law, 32, 29-70.

Sykes, G. (2007). The society of captives: a study of a maximum security prison. Princeton: Princeton University Press.

Taylor, C. (2015). Gendered pathways to recidivism: differential effects of family support by gender. Women \& Criminal Justice, 25(1), 169-183.

Thomas, C. \& Foster, S. (1973). The importation model perspective on inmate social roles: an empirical test. Sociological Quarterly, 14, 226-234.

Thomas, C. \& Peterson, D. (1977). Prison organization and inmate subcultures. Indianapolis, IN: The BobbsMerrill Company, Inc.

Tietjen, G., Garneau, C., Horowitz, V., \& Noel, H. (2018). Showing up: the gendered effects of social engagement on education participation on U.S. correctional facilities. The Prison Journal, 98(3): 359-381.

Tracy, A., Smith, L., \& Steurer, S. (1998). Standing up for education: new CEA study seeks to definitively show correlation between education and reduced recidivism. Corrections Today, 60, 144-147.

Uggen, C. (2000). Work as a turning point in the life course of criminals: a duration model of age, employment, and recidivism. American Sociological Review, 65(4), 529-546.

Wright, E., Van Voorhis, P., Salisbury, E., \& Bauman, A. (2012). Gender responsive lessons learned and policy implications for women in prison: a review. Criminal Justice and Behavior, 39(12), 1612-1632. 


\section{Appendix A. Violent Infraction Description}

Homicide

Aggravated Assault/Inmate

Fighting

Threatening

Aggravated Assault/Visitor

Holding Hostage

Disease Transfer

Cause Inmate Injury

Aggravated Assault/Staff

Sexual Assault Staff

Attempted Sexual Assault/Staff

Abusive Sexual Contact/Staff

Assault/Inmate

Assault/Offender

Sexual Assault/Offender

Attempted Sexual Assault/Offender

Abusive Sexual Contact/Offender

Rioting

Inciting Riot

Strong Arming/Intimidation

Cause Staff Injury

Assault/Non-Hospital

Assault/Staff

Assault/Visitor

Refuse w/ Staff Injury

Resist Order w/ Staff Injury

Injure a Visitor

Assault/Hospital

Assault

Holding Hostage

Refuse Medical Order/Injury 
